\title{
Monitoring the changes in land use and landscape pattern in recent 20 years: A case study in Wuhan, China
}

\author{
Yuwei Wang ${ }^{1, *}$, Kaicheng $\mathrm{Wu}^{1}$, and Wang $\mathrm{Gao}^{1}$ \\ ${ }^{1}$ School of Artificial Intelligence, Jianghan University, Wuhan 430056, China
}

\begin{abstract}
Based on the land use data of 2000, 2010 and 2020, using GIS technology along with landscape ecology methods, this paper monitored the changes in land use and landscape pattern in Wuhan. The findings are as follows: (1) the main features of land use change in Wuhan were the expansion of urban area and the decline of cropland, forest, wetland and water in recent 20 years; (2) forest, wetland and water kept a transfer-out trend while urban kept a transfer-in trend; (3) the fragmentation degree of forest, grassland and urban landscapes decreased from 2000 to 2020; (4) the patch shapes of almost all landscapes tended to be more regular under the human interventions. It is thereby worth reducing the interference intensity of human activities on landscape pattern in the process of urban growth.
\end{abstract}

\section{Introduction}

Land use and cover change (LUCC) depicts the spatial pattern of the earth's surface, and reflects the interaction between natural processes and human society, as well as serves as an important part of global environmental change and sustainable development [1-3]. Previous researches suggest that with the in-depth development of the urbanization process, significant changes have taken place in land use and landscape pattern in many places around the world $[4,5]$.

Wuhan is a representative metropolis in terms of its rapid urbanization process over the last two decades. The fast growth of economy and the continuous expansion of the built-up areas lead to the dynamics of land use in Wuhan, which has a remarkable impact on the economic and ecological pattern of Wuhan [6,7]. It is of great importance to analyze the changes of land use and landscape pattern, and preferably, to provide decisionmaking reference for urban planning strategies and policies.

Our main objectives in this study are: (1) to examine the changes of land use using time-series images taken in 2000, 2010, and 2020; (2) to investigate the variations of landscape pattern by calculating landscape metrics; (3) to provide scientific suggestions for optimizing land use and landscape pattern.

\section{Study area, data and methodology}

\subsection{Study Area}

Wuhan is located in central China, and its geographic coordinates are $29^{\circ} 58^{\prime}$ to $31^{\circ} 22^{\prime} \mathrm{N}$ and $113^{\circ} 41^{\prime}$ to $115^{\circ} 05^{\prime}$ E. The whole city covers an area of $8569.15 \mathrm{~km}^{2}$, including 13 administrative districts [8]. The climate of the city belongs to typical subtropical monsoon climate, with four distinct seasons. According to the statistics, the average annual precipitation is $1269 \mathrm{~mm}$, and mainly occurs in the summer. The average annual temperature is $15.8^{\circ} \mathrm{C}-17.5^{\circ} \mathrm{C}$. In past few years, accompanied by accelerated development of the economy and increased population in the region, significant changes in land use and landscape pattern were observed in previous studies $[9,10]$.

\subsection{Data}

The land use data were originated from the 30 meter global land cover dataset GlobeLand30 in this study. GlobeLand30 dataset are important achievements for global land cover remote sensing mapping project, and the dataset provide global land cover for the years 2000, 2010 and 2020 with high classification accuracy [11]. Since GlobeLand30 were separated into different tiles, the land use images containing Wuhan area were acquired. After that, the acquired images were mosaicked into one using ArcGIS 10.2. Then the land use images were clipped by the boundary of Wuhan city. Finally we obtained three land use classification images for 2000, 2010 and 2020. As shown in Figure 1, the study area comprised seven types of land use, including cropland, forest, grassland, wetland, water, urban and bare land.

\subsection{Methodology}

The land use transfer in/out rate and land use change matrix were applied to explore the characteristics of land use change in Wuhan in recent 20 years. The transfer in/out rate of land use indicates the extent to which a

* Corresponding author: weberwang@jhun.edu.cn 


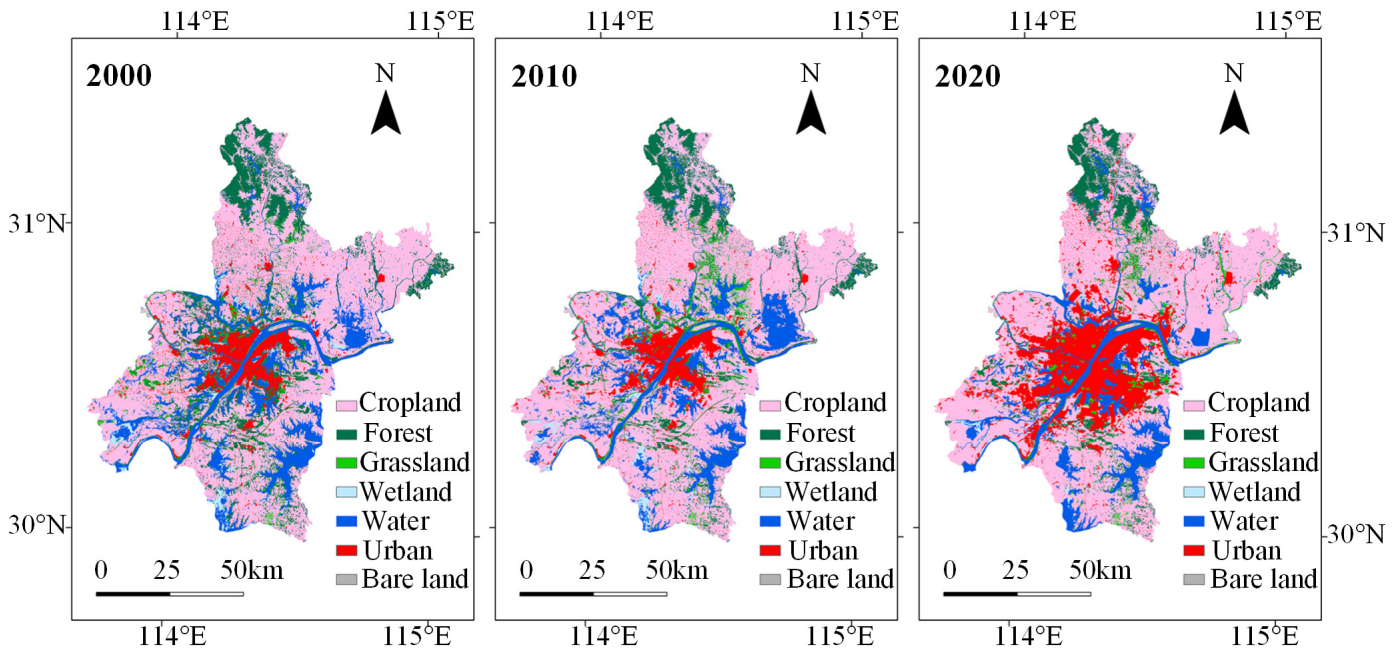

Fig. 1. Land use map for year 2000, 2010 and 2020 in Wuhan.

certain land type is transferred to or from other land types during the designated study period. Furthermore, the land use change matrix is an effective tool to reflect the mutual transfer of land use types in a certain time interval, so as to grasp the transfer trend of land use change process.

Two typical landscape metrics, i.e., patch density (PD) and landscape shape index (LSI), which measure the fragmentation and complexity of landscapes respectively, were adopted to estimate the changes in landscape pattern. PD represents the number of patches per unit area and is an important indicator of landscape fragmentation. Higher PD values represent greater fragmentation degree of the landscape. PD is defined below:

$$
P D_{i}=N_{i} / A
$$

Where $\mathrm{N}_{\mathrm{i}}$ represents the number of patches in the landscape of land type i, A is the total landscape area.

LSI is measured by the degree of deviation between a patch shape and a circle with the same area. It is a measure of the complexity of the patch shape associated with land use. It is calculated as follows:

$$
L S I=P / 2 \sqrt{\pi A}
$$

Where $\mathrm{P}$ is the patch perimeter, $\mathrm{A}$ is the patch area. A higher LSI value means a more complex landscape. All the landscape metrics were calculated by the FRAGSTATS (v4.2.1) software.

\section{Result}

\subsection{Changes in land use in Wuhan during 2000- 2020}

Overall, in recent 20 years, Wuhan has experienced an increment in the area of urban and bare land. Total urban area in Wuhan increased from $611.46 \mathrm{~km}^{2}$ in 2010 to $1537.69 \mathrm{~km}^{2}$ in 2020 (Table 1), an expansion of almost $150 \%$. The area of cropland, forest land, wetland and water decreased, of which cropland decreased by 74.16 $\mathrm{km}^{2}$, forest land by $442.68 \mathrm{~km}^{2}$, wetland by $96.05 \mathrm{~km}^{2}$ and water by $307.53 \mathrm{~km}^{2}$. The grassland area increased during 2000-2010 and then decreased from 2010-2020.

Table 1. Area of different land use types $\left(\mathrm{km}^{2}\right)$ in Wuhan from 2000 to 2020.

\begin{tabular}{cccc}
\hline Land use & $\mathbf{2 0 0 0}$ & $\mathbf{2 0 1 0}$ & $\mathbf{2 0 2 0}$ \\
\hline Cropland & 4889.14 & 5216.68 & 4814.98 \\
Forest & 1291.84 & 1026.60 & 849.16 \\
Grassland & 223.58 & 286.43 & 223.82 \\
Wetland & 133.33 & 120.35 & 37.28 \\
Water & 1425.29 & 1274.70 & 1117.76 \\
Urban & 611.46 & 646.47 & 1537.69 \\
Bare land & 6.46 & 9.87 & 8.37 \\
\hline
\end{tabular}

Table 2 and 3 demonstrate the land use change matrix and land use transfer in/out rate. From 2000 to 2010 , the transfer-in rate of cropland was $14.31 \%$, and the transfer-out rate was $8.56 \%$. The increase of cropland area mainly included $348.06 \mathrm{~km}^{2}$ of forest and 251.27 $\mathrm{km}^{2}$ of water. The forest mainly converted to cropland with the transfer-out rate $41.18 \%$. The transfer-in rate of grassland was $54.55 \%$, which was higher than the transfer-out rate. $58.17 \mathrm{~km}^{2}$ of cropland transferred into grassland. The wetland area changed within a narrow range, the transfer-in rate was almost similar with transfer-out rate. The transfer-in rate of urban land was slightly higher than the transfer-out rate, and $75.82 \mathrm{~km}^{2}$ of the cropland were converted to urban land. The total area of bare land accounted for a small proportion in the study area, and increased from 2000 to 2010.

During 2010 to 2020, remarkable urbanization process has been witnessed in this period. The transfer-in rate of urban was approximately $61.15 \%$, cropland $\left(737.84 \mathrm{~km}^{2}\right)$, forest $\left(61.19 \mathrm{~km}^{2}\right)$, grassland $\left(70.58 \mathrm{~km}^{2}\right)$ and water $\left(69.35 \mathrm{~km}^{2}\right)$ were converted to urban areas. In addition to transfer into urban area, $124.10 \mathrm{~km}^{2}$ of forest has been transferred out to cropland, which leads to the further reduction of forest area. Meanwhile, a significant reduction in wetland was observed, $68.65 \mathrm{~km}^{2}$ of the wetland was transferred to water, and the transfer-out rate was up to $78.03 \%$. 
Table 2. Land use change matrix and the rate of change in Wuhan from 2000 to 2010.

\begin{tabular}{ccccccccc}
\hline 2000-2010 & Cropland & Forest & Grassland & Wetland & Water & Urban & $\begin{array}{c}\text { In rate } \\
(\%)\end{array}$ & $\begin{array}{c}\text { Out rate } \\
(\%)\end{array}$ \\
\hline Cropland & 4470.40 & 121.49 & 58.17 & 5.03 & 157.29 & 75.82 & 14.31 & 8.56 \\
Forest & 348.06 & 759.85 & 36.37 & 8.37 & 94.34 & 42.20 & 25.98 & 41.18 \\
Grassland & 21.06 & 55.71 & 130.19 & 1.63 & 4.11 & 10.89 & 54.55 & 41.77 \\
Wetland & 41.43 & 7.18 & 4.20 & 50.91 & 28.02 & 1.30 & 57.70 & 61.81 \\
Water & 251.27 & 73.09 & 46.24 & 54.23 & 988.96 & 8.95 & 22.42 & 34.23 \\
Urban & 83.72 & 7.04 & 11.27 & 0.18 & 1.94 & 507.31 & 21.53 & 17.03 \\
Bare land & 0.74 & 2.23 & 0.00 & 0.01 & 0.04 & 0.00 & 65.11 & 46.69 \\
\hline
\end{tabular}

Table 3. Land use change matrix and the rate of change in Wuhan from 2010 to 2020.

\begin{tabular}{ccccccccc}
\hline 2010-2020 & Cropland & Forest & Grassland & Wetland & Water & Urban & $\begin{array}{c}\text { In rate } \\
(\%)\end{array}$ & $\begin{array}{c}\text { Out rate } \\
(\%)\end{array}$ \\
\hline Cropland & 4166.09 & 92.88 & 49.70 & 7.01 & 165.21 & 737.84 & 13.44 & 20.20 \\
Forest & 124.10 & 702.09 & 64.92 & 0.41 & 71.59 & 61.19 & 17.24 & 31.63 \\
Grassland & 47.60 & 42.05 & 93.99 & 0.09 & 32.30 & 70.58 & 57.96 & 67.25 \\
Wetland & 23.07 & 1.23 & 0.15 & 26.43 & 68.65 & 0.82 & 29.10 & 78.03 \\
Water & 415.62 & 4.38 & 8.35 & 3.33 & 773.40 & 69.35 & 30.73 & 44.90 \\
Urban & 36.24 & 3.01 & 6.61 & 0.01 & 3.70 & 597.39 & 61.15 & 7.67 \\
Bare land & 0.47 & 2.82 & 0.00 & 0.00 & 2.05 & 0.46 & 51.02 & 58.72 \\
\hline
\end{tabular}

\subsection{Changes in landscape pattern in Wuhan during 2000-2020}

As shown in Table 4, the PD values of cropland, forest and grassland showed an increasing trend from 2000 to 2010, but then decreased after 2010. Most of the above areas were covered by green vegetation, the changing trajectory indicated that green patches became more fragmented in 2000-2010, but the situation had improved after 2010. Conversely, the PD values of wetland decreased from 0.03 to 0.02 during 2000-2010, then reaching a higher value 0.04 afterwards. It reminded the municipal government to pay more attention to the protection of wetlands. Noticeably, the PD values of water and urban kept a gradual weaken trend, indicating that the water and urban patches tend to be concentrative.

Table 4. Patch density values of landscape in Wuhan for the period 2000-2020.

\begin{tabular}{cccc}
\hline Land use & $\mathbf{2 0 0 0}$ & $\mathbf{2 0 1 0}$ & $\mathbf{2 0 2 0}$ \\
\hline Cropland & 0.31 & 0.42 & 0.36 \\
Forest & 2.62 & 3.45 & 1.98 \\
Grassland & 1.56 & 1.95 & 1.54 \\
Wetland & 0.03 & 0.02 & 0.04 \\
Water & 0.76 & 0.31 & 0.08 \\
Urban & 0.59 & 0.43 & 0.38 \\
Bare land & 0.14 & 0.16 & 0.15 \\
\hline
\end{tabular}

The variation of LSI values is listed in Table 5 . Except for grassland, the LSI values of other land use types experienced a decreasing trend. Specially, the LSI value of grassland increased to some extent from 2000 to 2010, subsequently reaching to a lower value from 2010 to 2020 . In general, the complexity of most landscapes decreased during 2000-2020.
Table 5. Landscape shape index values of landscape in Wuhan for the period 2000-2020.

\begin{tabular}{cccc}
\hline Land use & $\mathbf{2 0 0 0}$ & $\mathbf{2 0 1 0}$ & $\mathbf{2 0 2 0}$ \\
\hline Cropland & 93.64 & 85.68 & 76.41 \\
Forest & 185.78 & 177.02 & 134.78 \\
Grassland & 151.62 & 169.22 & 136.50 \\
Wetland & 38.18 & 22.92 & 20.69 \\
Water & 87.38 & 60.92 & 41.52 \\
Urban & 67.96 & 56.86 & 48.21 \\
Bare land & 39.55 & 37.70 & 37.75 \\
\hline
\end{tabular}

\section{Discussion}

Monitoring the changes of land use and landscape pattern are of great significance for making sustainable land-use policies $[12,13]$. In this research, based on the analysis of land use change matrix, land use transfer rate and landscape metrics, the dynamics in land use and landscape pattern in Wuhan from 2000 to 2020 were explored.

It was found that human activities had significant impact on land use and landscape pattern in recent 20 years. The main characteristics of land use change in Wuhan were the increase of urban and the decrease of cropland, forest, wetland and water in recent 20 years. This reflects the enhancement of human activity intensity accompanied by the city development. With the expansion of built-up areas, a great deal of cropland, forest and water were occupied. The transfer-out rates into urban for cropland, forest and water were enlarged at large scale. It is worth noting that the area of cropland and grassland recovered during 2000-2010. This is mainly ascribed to the implementation of land use planning policies for protecting urban green spaces proposed by local government. Nevertheless, it seems that some of these policies have not achieved the goals. 
The process of urbanization was further intensified from 2010-2020.

The landscape metrics further confirmed the human interventions on landscape patterns. The dynamic of PD and LSI values revealed that the distribution of most landscapes became less fragmented and more regular from 2000 to 2020 . Under the human intervention, the distribution of landscape tends to be concentrated. Meanwhile, the urbanization process has transformed the boundary of land patches, making it more simplified.

The current work employed the GlobeLand 30 dataset and two landscape metrics to analyze the land use and landscape pattern changes. The future work will include more land use datasets and landscape metrics, which can theoretically expand the scope of research.

\section{Conclusion}

This study combined land use data with landscape ecology method to illustrate the changes in land use and landscape pattern in Wuhan in the past two decades. The result showed that along with economic development and population growth, the urban area of Wuhan expanded substantially, but the cost was the reduction of city green spaces. Furthermore, the fragmentation and complexity level of the landscape pattern significantly changed, which further proved that human intervention affected the distribution of landscape patterns. Our study highlights the urgent need for governments to develop careful policies to control human activities.

\section{References}

1. Z. T. Li, M. Li, and B. C. Xia, Ecol. Indic. 114, 106319 (2020)

2. C. Faichia, Z. Tong, J. Zhang, X. Liu, E. Kazuva, K. Ullah, and B. Al-Shaibah, Sustain. 12, 1 (2020)

3. W. Bi, B. Weng, Z. Yuan, M. Ye, C. Zhang, Y. Zhao, D. Yan, and T. Xu, Int. J. Environ. Res. Public Health 15, 1724 (2018)

4. S. B. Asabere, R. A. Acheampong, G. Ashiagbor, S. C. Beckers, M. Keck, S. Erasmi, J. Schanze, and D. Sauer, Land Use Policy 96, 104707 (2020)

5. V. Anand and B. Oinam, Remote Sens. Lett. 11, 225 (2020)

6. X. Zhou and H. Chen, Sci. Total Environ. 635, 1467 (2018)

7. S. Zhu, X. Kong, and P. Jiang, J. Rural Stud. 77, 75 (2020)

8. Y. Liu, T. Luo, Z. Liu, X. Kong, J. Li, and R. Tan, Habitat Int. 47, 113 (2015)

9. Q. He, Y. Liu, C. Zeng, Y. Chaohui, and R. Tan, Int. J. Geogr. Inf. Sci. 31, 1907 (2017)

10. Y. Zhang, K. Qin, Q. Bi, W. Cui, and G. Li, Remote Sens. 12, (2020)

11. C. Jun, Y. Ban, and S. Li, Nature 514, 434 (2014)

12. B. Wijesiri, K. Deilami, and A. Goonetilleke, Environ. Pollut. 234, 480 (2018)
13. G. Li, F. Zhang, Y. Jing, Y. Liu, and G. Sun, Sci. Total Environ. 596-597, 256 (2017) 